\title{
An evaluation of the utility of web development methods
}

\author{
Sheridan Jeary $\cdot$ Keith Phalp $\cdot$ Jonathan Vincent
}

Published online: 10 January 2009

(C) Springer Science+Business Media, LLC 2009

\begin{abstract}
Although many web development methods exist, they are rarely used by practitioners. The work reported here, seeks to explain why this might be so, and suggests that, for many, the perceived benefits may be outweighed by the difficulty or effort required to learn the method. In attempting to gauge the utility of methods the authors undertook a 2-year study of 23 small web development projects, attempting to use a range of published (academic) methods. Of the 23 projects we found only one case where the developer continued to use an academic web development method throughout the lifecycle. The ability to understand a method and/or its techniques was repeatedly cited as the reason for its abandonment. Our findings also indicate a number of key areas, relating to terminology, completeness, and guidance, where existing methods may be failing their intended users. In attempting to further our understanding of web development methods we completed a comprehensive survey of web development methods; covering 52 web development methods, encompassing a range of different research communities, and drawing upon 63 different sources. Our findings here shed some light upon the confusion of methods for the would-be user. In summary, the findings are that, although there is much of value in a variety of methods, method choice is somewhat bewildering for the newcomer to the field, and many methods are incomplete in some dimension. By providing this work we hope to go some way towards supporting the software engineering community, in both academia and industry, in their understanding of the quality issues that exist with the take up and use of web development methods.
\end{abstract}

Keywords Web development · Web development methods · Web development projects

S. Jeary $(\bowtie) \cdot$ K. Phalp $\cdot$ J. Vincent

Software Systems Research Centre, Bournemouth University, Fern Barrow, Poole BH12 5BB, UK

e-mail: sjeary@bournemouth.ac.uk

URL: www.sosym.co.uk

K. Phalp

e-mail: kphalp@bournemouth.ac.uk

J. Vincent

e-mail: jvincent@bournemouth.ac.uk 